\title{
EVALUATION OF INTERACTIONS BETWEEN RETARDING ADMIXTURES AND FINE MATERIALS IN LONG-TERM FLOWABILITY CEMENT PASTES
}

\author{
Eduardo Nobre Guindani ${ }^{(1)}$; Malik Cheriaf ${ }^{(2)}$; Janaíde Cavalcante Rocha ${ }^{(3)}$ \\ (1) Federal University of Santa Catarina, Post-Graduate Program in Civil Engineering \\ (2) University Federal of Santa Catarina, Department of Civil Engineering \\ (3) University Federal of Santa Catarina, Department of Civil Engineering
}

https://doi.org/10.21452/bccm4.2018.02.18

\begin{abstract}
The retarding effects in the hydration of Portland cement caused by organic molecules such as gluconates, sucrose and organic acids are mainly used to setting control required for the production of ready-mix-mortars. Three commercial products, indicated for the control of hydration reactions of Portland cement, were evaluated regarding to maintain the flowability over time of cement pastes containing additions of fine materials $(<75 \mu \mathrm{m})$. The cement pastes were produced with replacement of the cement up to $50 \%$ (by weight) by fine materials $(\mathrm{d}<75 \mu \mathrm{m})$ : basalt filler; fly ash; quartz filler; perlite filler (perlite was replaced by volume). The organic admixtures were used by 0.5 to $1.0 \%$ (by weight of cement). Changes in the flowability of the cement pastes over time were evaluated through mini-flow tests and rheometer measurements. The results demonstrate an important reduction in the shear stress of the cement pastes under the effect of the organic molecules, as a consequence of the homogenization of the ionic charges on the surface of the particles. In addition, all organic admixtures at a dosage of $1.0 \%$ were able to maintain the flowability for more than 400 hours, however, with gradual reductions of the mini-flow scattering throughout this period, resulting from a probable partial hydration of the cement. The cement pastes with basalt filler showed a faster reduction of flowability over time, which may indicate reactivity between the mineral particles of the filler and the organic molecules. On the other hand, quartz filler contribute to the increase in initial flow. Calorimeter measurements were used to evaluate the interactions between the fine material and the organic molecules confirming that the basalt filler actually reduces the effect of the admixtures.
\end{abstract}

\section{INTRODUCTION}

The retarding effects on cement hydration caused by organic molecules, mainly gluconates and sucrose, are explored to control the hydration time of cementitious materials. Depending on 
the dosage used, these molecules can retard the setting time of cement for more than 72 hours and are used to prolong the fresh state of mortar and concrete [1][2].

In ready-mix mortar fine materials, either inert fillers or pozzolanic fines, are added to the cementitious materials to improve properties on fresh state, such as cohesion and flowability, as well as to improve mechanical properties, compressive strength, and specially to reduce porosity of system. These fine materials can change the hydration kinetics and interact with the organic molecules present in the mixes. In this sense, when retarding admixtures are used in conjunction with fine materials, significant changes in the retardation time can be observed, often reducing the efficiency of the chemical admixtures [3].

Researches have been carried out aiming to evaluate additions of fine materials with quite different physicochemical characteristics, under the effect of retard admixtures (designed for manufacture of ready-mix-mortar). It was known to evaluate mainly changes in the hydration kinetics wich can be associated to the interaction between the chemical admixtures and the fine materials. In addition, the research was supplemented by evaluation of the fluidity and rheological properties of cement pastes over time during the period that they remained on fresh state.

\section{MATERIALS AND METHODS}

\subsection{Materials}

Brazilian cement type CP II F-32 was used to produce the cement pastes. The fine materials were: Basalt filler (BF) - Residual; Fly ash (FA) - Pozzolanic; Quartz filler (QF) - Inert; Perlite (PT) - Lightweight. All the fines were sieved to obtain particles less than $75 \mu \mathrm{m}$.

The main physico-chemical characteristics of these materials are presented in Table 1 . The measurement of the particle size distribution was performed using Mastersizer 2000 equipment. The chemical composition of the total oxides present in the materials was carried out using Shimatzu EDX-7000 equipment. In addition, complementary characteristics such as specific surface (Blaine) and loss on ignition were determined.

Table 1 : Chemical and physical characteristics of materials.

\begin{tabular}{c|ccccccccc}
\hline $\begin{array}{c}\text { Sample } \\
\text { Notation }\end{array}$ & $\begin{array}{c}\text { Density } \\
\left(\mathbf{g} / \mathbf{c m}^{3}\right)\end{array}$ & $\begin{array}{c}\text { Surface } \\
(\mathbf{B l a i n e )} \\
\left(\mathbf{c m}^{2} / \mathbf{g}\right)\end{array}$ & $\begin{array}{c}\mathbf{d}_{\mathbf{5 0}} \\
\mathbf{( \mu m )}\end{array}$ & $\begin{array}{c}\mathbf{d}_{\mathbf{1 0}} \\
\mathbf{( \mu m )}\end{array}$ & $\begin{array}{c}\mathbf{S i O}_{2} \\
\mathbf{( \% )}\end{array}$ & $\begin{array}{c}\mathbf{A l}_{\mathbf{2}} \mathbf{O}_{3} \\
\mathbf{( \% )}\end{array}$ & $\begin{array}{c}\mathbf{C a O} \\
\mathbf{( \% )}\end{array}$ & $\begin{array}{c}\mathbf{F e}_{\mathbf{2}} \mathbf{O}_{3} \\
\mathbf{( \% )}\end{array}$ & $\begin{array}{c}\text { Loss on } \\
\text { ignition } \\
\mathbf{( \% )}\end{array}$ \\
\hline $\mathbf{F A}$ & 2.087 & 3594.2 & 32.15 & 9.92 & 70.18 & 12.75 & 5.24 & 5.82 & 1.06 \\
$\mathbf{B F}$ & 2.542 & 2599.4 & 34.13 & 4.71 & 76.55 & 14.33 & 0.82 & 1.13 & 1.57 \\
$\mathbf{Q F}$ & 2.618 & 2687.6 & 38.91 & 3.43 & $(>99)$ & - & - & - & - \\
$\mathbf{P T}$ & 1.110 & 8269.9 & 58.93 & 19.71 & 61.06 & 27.32 & 249 & 2.47 & 3.17 \\
Cement & 3.081 & 3267.0 & 21.18 & 4.73 & 18.48 & 4.19 & 60.47 & 2.97 & 5.12 \\
\hline
\end{tabular}

Three different commercial retarding admixtures were used (indicated mainly for the manufacture of ready-mix-mortars). They were identified as POW; ETM; MR; and are composed by organic molecules such as gluconates and sucrose. These products were evaluated at concentrations of 0.5 and $1.0 \%$ in the initial mini-flow studies, although the remainder of the research was used $0.5 \%$.

The composition of the mixes is shown in Table 2. All samples were produced following the same mixing and storage procedure. After mixing the pastes in a standard mixer to mortars, the samples were stored in a hermetically sealed polyethylene container to prevent water evaporation and any contact with the environment, and kept at room temperature of $23 \pm 1^{\circ} \mathrm{C}$. 
Table 2 : Mix proportion of sample (wt).

\begin{tabular}{c|ccccccccc}
\hline Sample Notations & $\begin{array}{c}\text { Cement } \\
(\mathrm{g})\end{array}$ & $\begin{array}{c}\text { BF } \\
(\mathrm{g})\end{array}$ & $\begin{array}{c}F A \\
(\mathrm{~g})\end{array}$ & $\begin{array}{c}\text { QF } \\
(\mathrm{g})\end{array}$ & $\begin{array}{c}P T \\
(\mathrm{~g})\end{array}$ & $\begin{array}{c}\text { Água } \\
(\mathrm{g})\end{array}$ & $\begin{array}{c}\text { POW } \\
(\mathrm{g})\end{array}$ & $\begin{array}{c}\text { ETM } \\
(\mathrm{g})\end{array}$ & $\begin{array}{c}M R \\
(\mathrm{~g})\end{array}$ \\
\hline Ref.100\%C & 400 & 0 & 0 & 0 & 0 & 180 & 0 & 0 & 0 \\
Ref.50\%BF & 200 & 200 & 0 & 0 & 0 & 180 & 0 & 0 & 0 \\
Ref.50\%FA & 200 & 0 & 200 & 0 & 0 & 180 & 0 & 0 & 0 \\
Ref.50\%QF & 200 & 0 & 0 & 200 & 0 & 180 & 0 & 0 & 0 \\
Ref.50\%PT & 200 & 0 & 0 & 0 & $72.1 *$ & $240^{*}$ & 0 & 0 & 0 \\
100\%C.0,5\%POW & 400 & 0 & 0 & 0 & 0 & 180 & 2.00 & 0 & 0 \\
100\%C.0,5\%ETM & 400 & 0 & 0 & 0 & 0 & 180 & 0 & 2.00 & 0 \\
100\%C.0,5\%MR & 400 & 0 & 0 & 0 & 0 & 180 & 0 & 0 & 2.00 \\
50\%BF.0,5\%POW & 200 & 200 & 0 & 0 & 0 & 180 & 1.00 & 0 & 0 \\
50\%FA.0,5\%POW & 200 & 0 & 200 & 0 & 0 & 180 & 1.00 & 0 & 0 \\
50\%QF.0,5\%POW & 200 & 0 & 0 & 200 & 0 & 180 & 1.00 & 0 & 0 \\
50\%PT.0,5\%POW & 200 & 0 & 0 & 0 & $72.1 *$ & $240^{*}$ & 1.00 & 0 & 0 \\
50\%BF.0,5\%ETM & 200 & 200 & 0 & 0 & 0 & 180 & 0 & 1.00 & 0 \\
50\%FA.0,5\%ETM & 200 & 0 & 200 & 0 & 0 & 180 & 0 & 1.00 & 0 \\
50\%QF.0,5\%ETM & 200 & 0 & 0 & 200 & & 180 & 0 & 1.00 & 0 \\
50\%PT.0,5\%ETM & 200 & 0 & 0 & 0 & $72.1 *$ & $240^{*}$ & 0 & 1.00 & 0 \\
50\%BF.0,5\%MR & 200 & 200 & 0 & 0 & 0 & 180 & 0 & 0 & 1.00 \\
50\%FA.0,5\%MR & 200 & 0 & 200 & 0 & 0 & 180 & 0 & 0 & 1.00 \\
50\%QF.0,5\%MR & 200 & 0 & 0 & 200 & 0 & 180 & 0 & 0 & 1.00 \\
50\%PT.0,5\%MR & 200 & 0 & 0 & 0 & $72.1 *$ & $240^{*}$ & 0 & 0 & 1.00 \\
\hline
\end{tabular}

* The mixes with perlite were calculated by volumetric substitution, due to their low bulk density. It was necessary to increase $60 \mathrm{~g}$ of water in each sample in order to achieve the minimum flowability for the tests.

\subsection{Flowability measurements}

To determine the behavior of the cement pastes under the effect of the chemical admixtures, mini-slump test was used. The flow measurements were performed over time. To evaluate the results, the diameter of spreading the base of the mini-cone $(40 \mathrm{~mm})$ was taken as reference for calculating the Flow Index accorAlsoding to Equation 1:

$$
F I=\left(\frac{\text { Flow }_{(t)}-40}{\text { Flow }_{(\mathrm{to})}-40}\right) * 100 \quad \text { Equation (1). }
$$

FI = Flow Index (\%); Flow $_{(\mathrm{t})}=$ flow on time “t” $(\mathrm{mm})$ Flow $_{(\mathrm{t})}=$ initial flow $(\mathrm{mm})$.

The pastes with fines were evaluated in a Haake Mars Rheometer in order to determine the changes of the shear stress over time. The measurement methods was similar to that used by [4]. Measurements were made at 6-second steps, increasing the shear rate from $1^{\text {-sec }}$ to $60^{\text {-sec }}$ in $3 \mathrm{~min}$. The geometry used was a smooth cylinder. A pre-shear of 30s was performed and the samples were kept at constant temperature of $24^{\circ} \mathrm{C}$. The pastes were evaluated at times: 0 ; $3 \mathrm{~h}$; 24h and 48 hours.

\subsection{Reaction kinetic measurements}

The evaluation of the hydration processes was performed in a 6-channel semi-adiabatic calorimeter. The retarding effect caused by chemical admixtures, as well as the interference caused by fines, could be evaluated through the temperature curves of the pastes temperature. The differential temperature of each sample $\left(\Delta \mathrm{T}\right.$ in $\left.{ }^{\circ} \mathrm{C}\right)$ was used to generate the curves, which can be considered as the effective increase of heat caused by the cement hydration. $580 \mathrm{~g}$ of cement paste was used. All samples were initially at $24^{\circ} \mathrm{C}$. 


\section{RESULTS}

The initial results obtained from mini-slump test were important for the characterization of the performance of the chemical admixtures over time. As can be seen in Figure 1, these chemical products are able of prolonging the fresh state of the pastes for more than 80 hours at a dosage of $0.5 \%$ and more than 340 hours at a dosage of $1.0 \%$. In addition, distinct behaviors could be observed between them, which is most evident in samples made with $1.0 \%$. The pastes with MR leading a more pronounced reduction in the flowability of pastes regardless of the dosage used. The POW and ETM showed a great reduction in the flowability in the first hours after the mixture, which can be demonstrated in both tests: mini-slump and rheological measurements. However, between 48 and 96 hours after, the flowability of pastes was partially recovered for both. Further, a smooth and constant reduction of flowability is a characteristic pertinent to both (POW and ETM), and which becomes more evident in the pastes at a dosage of $1.0 \%$.
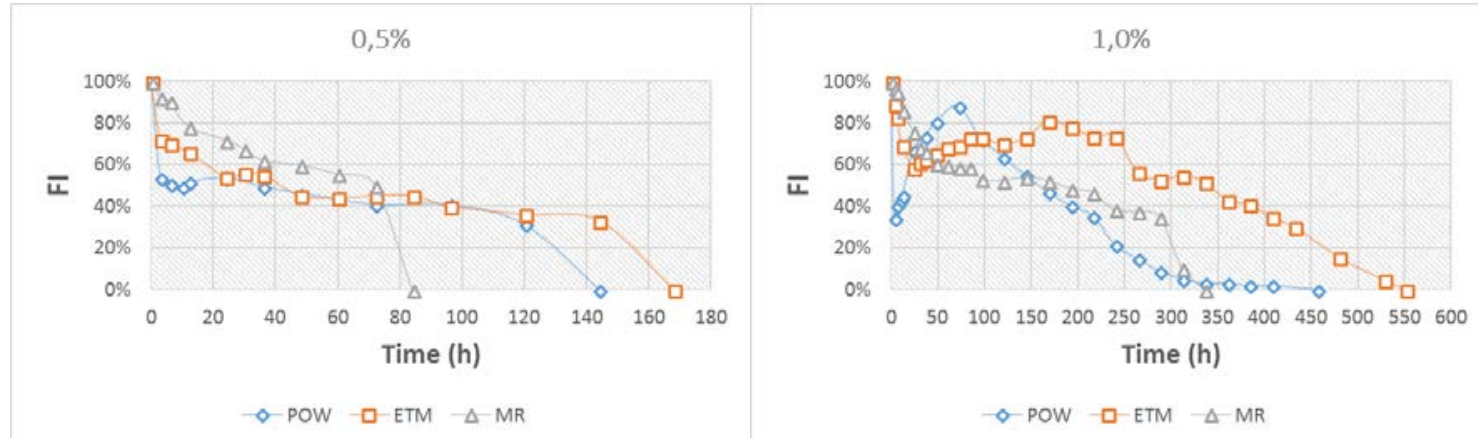

Figure 1 : Flow Index (FI) measurements over time

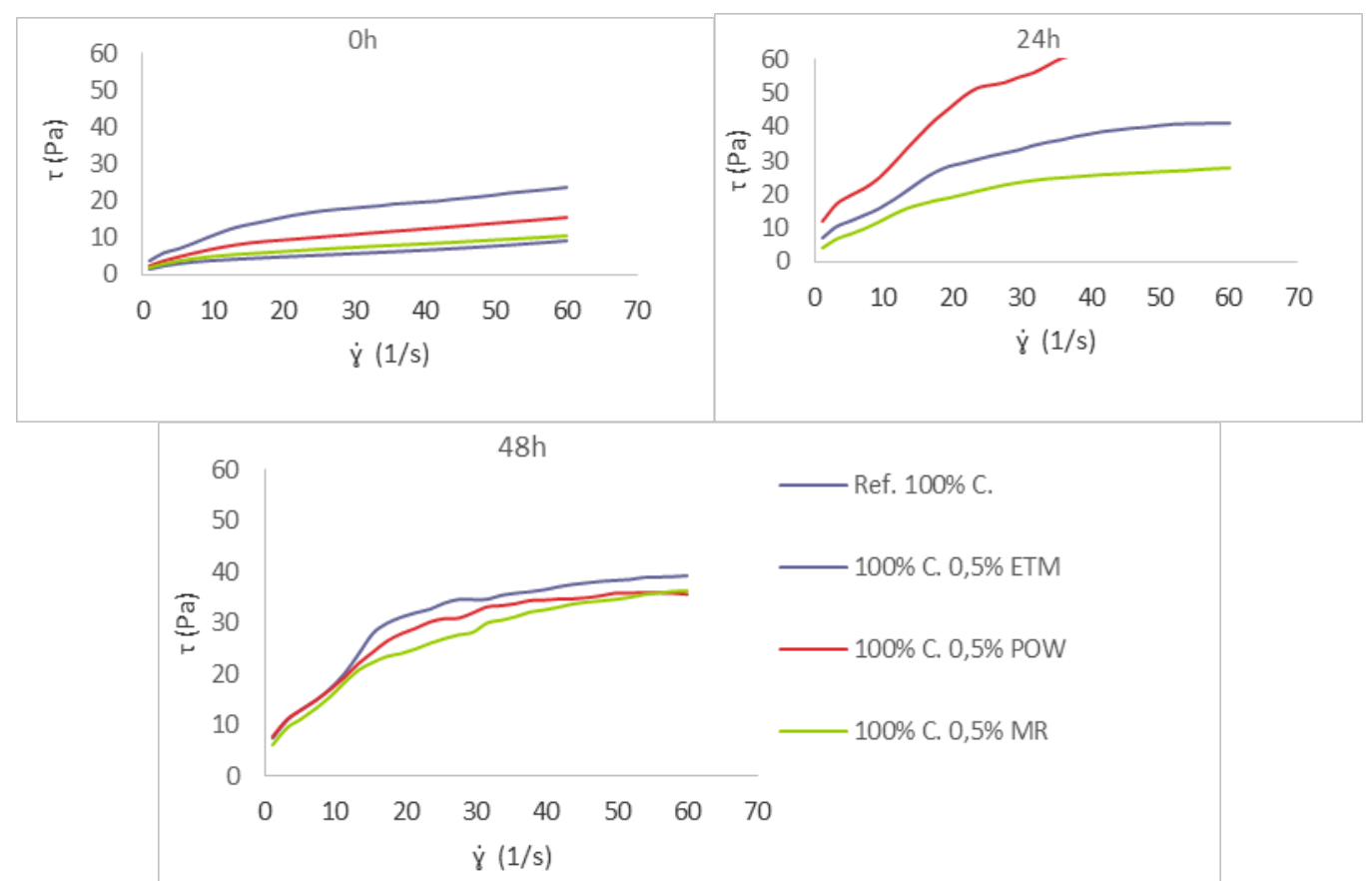

Figure 2 : Rheological measurements of pastes, $100 \%$ cement, over time.

A secondary effect that can be observed is the increase in the initial flowability of the pastes, which can be evidenced due the shear stress values of the samples with chemical admixtures were initially smaller than the reference paste, Figure 2. Comparing all the chemical products evaluated, the ETM presented lower initial shear stresses, as well as it kept the samples in the fresh state for longer, reaching 550 hours with $1.0 \%$ content (Figure 1). 
Among the different fines evaluated, the lowest shear stress was observed in QF sample. The highest stress was observed in the sample with BF, which was always higher than the others during the whole period of measurements. It is important to observe that the samples with $\mathrm{BF}$ and MR additive do not have data from 24h because the sample hardened before the measurement could be performed.

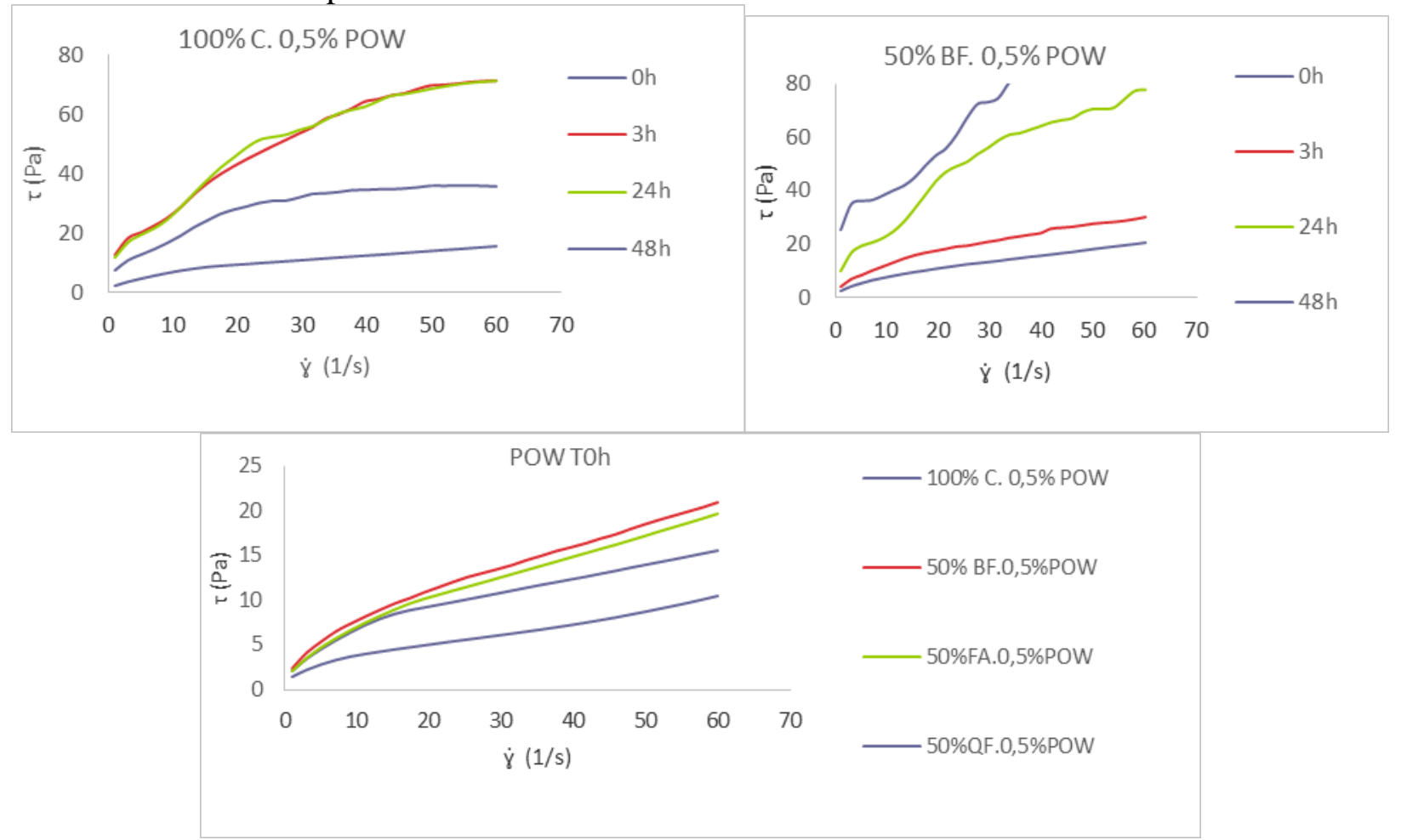

Figure 3 : Rheological measurements of POW pastes over time.

The results of the calorimetry are shown in Figure 4. The MR samples were that presented the earlier set time in all the comparatives, as could be observed in the evaluation of the fluidity over time. Even pastes with ETM was the samples that presented the peak of longer heat release.

The curve of temperature monitoring of the sample with ETM presented double peak of heat release. This phenomenon was observed exclusively for this sample. In addition, it is important to note that samples produced with fines and with ETM additive did not show temperature peaks up to 250 hours of testing when they were removed from the calorimeter.

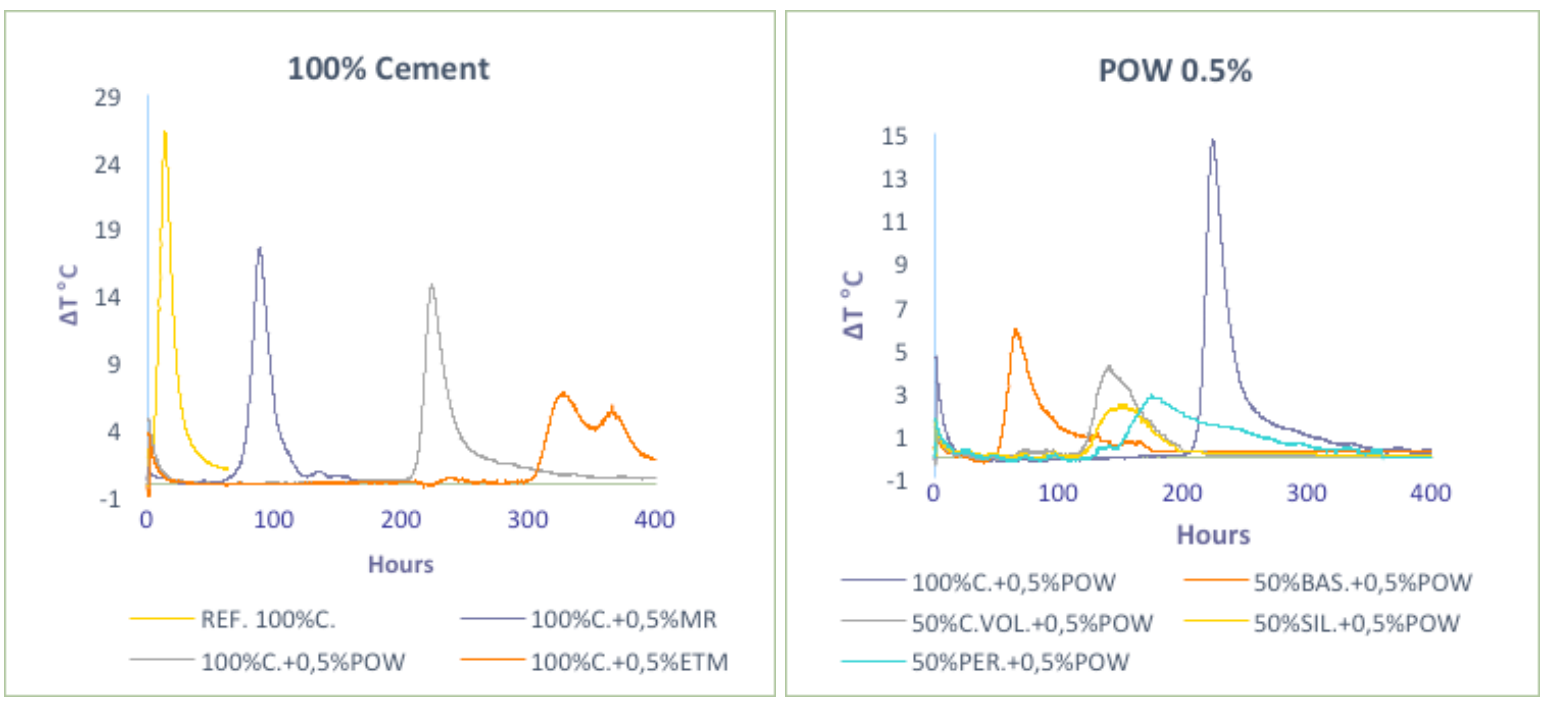




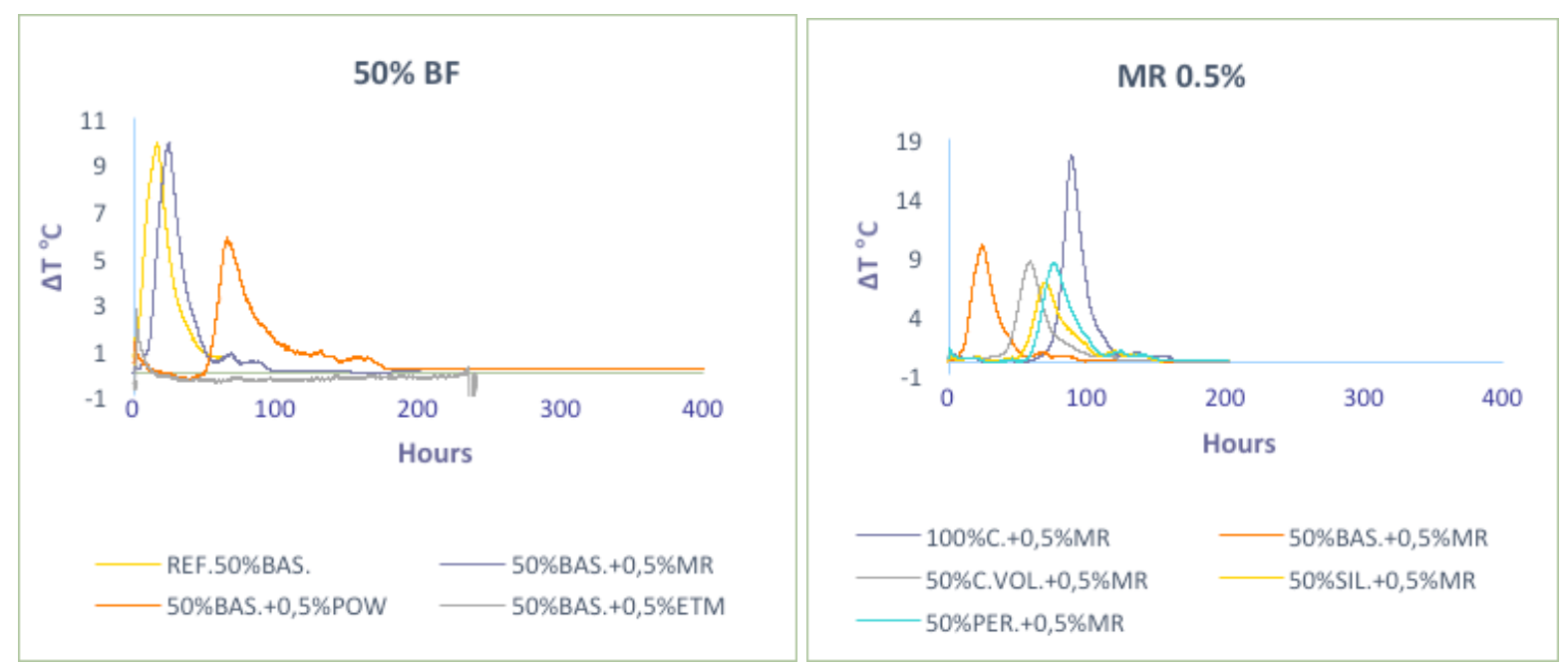

Figure 4 : Evaluation of temperature increase of cement pastes.

\section{DISCUSSION}

The flowability of the samples with POW in the mini-slump tests $(100 \%$ C. $+1.0 \%$ POW) and in the rheological study (100\% C. + 0.5\% POW) can be interpreted as a " false-set-time ", a behavior commonly presented by organic admixtures whose composition has sucrose. When added to cement materials before the sulfate phase has been consumed, sucrose accelerates the formation of ettringite, drastically reducing the fluidity of the mixes [5].

The considerable increase in the initial fluidity caused by the retarding admixtures was also observed by the authors [2] and [6] when evaluating mortars with sodium gluconate (organic molecules used like raw material by retarding admixtures). This behavior probably occurs due to the homogenization of the ionic charges of the surface of the particles, caused by the action of the organic molecules.

The gradual reduction of flowability (Figure 1), reaffirmed by the shear stress increase over time (Figure 2), is an evidence that hydration reactions may be occurring slowly in pastes, generating internal interparticle set [1]. A slow formation of ettringite could be the explanation for this phenomenon, since it is the main hydrate responsible for the reduction of flowability in cementitious materials, besides being the first hydrate formed during the hydration process.

The shear stress values of the samples with QF were always the lowest when compared to the other samples. This indicates a plasticizing effect of this material, which was also observed by [7]. This effect also contributed to the prolongation of fluidity over time, since this same behavior was observed also in $48 \mathrm{~h}$.

The behaviors observed in the calorimetry, comparing the curves with fines, is very similar to what was observed by [3]. The samples that contained fines, despite the effects of dilution of the clinker, were the ones that presented set time earlier than samples with $100 \%$ cement. Moreover, another factor that contributes to this behavior is the fact that the dosage of the chemical admixtures is on the cement mass and not on the binder (cement + fines).

The temperature curve of the sample $100 \%$ C. + 0.5\% ETM, presented double peak. This may have been a result of the sample segregation process during the time it remained in the calorimeter. Due to the high flowability of the material, formation of layers with different concentrations of cement may have occurred during the measurement period. Possibly the bottom layer with higher solids concentration reacted before the upper layer, with lower concentration of solid material.

The comparisons of calorimetry between the fines show that the samples with BF reacted sooner than the others. It is also important to note that the height of the temperature peaks of these samples is slightly higher than the other fines. In addition, the rheological tests point to a 
much larger shear stress increase over time for the BF samples. These facts indicate that BF considerably reduces the retarding effects of the organic molecules.

\section{CONCLUSIONS}

The retarding admixtures are able of promoting increased in initial flowability of the cementitious materials as well as maintaining the fresh state of cement pastes for more than 80 hours $(0.5 \%$ dosage $)$. The composition of different chemical bases, such as gluconates and sucrose, results in chemical admixtures with different behaviors, such as the POW, in which the effect of the "false-set-time" can be observed, followed by an increase in flowability in the following hours.

The BF considerably reduces the efficiency of the retarding admixtures, as evidenced by both the rheological study and the calorimetry study. On the other hand, the fine of QF flavors cause an increase in flowability and its maintenance over time.

\section{Acknowledgements}

We gratefully acknowledge financial support from the CNPq and CAPES.

\section{REFERENCES}

[1] CHEUNG, J., JEKNAVORIAN, A., ROBERTS, L., \& SILVA, D. Impact of admixtures on the hydration kinetics of Portland cement. Cement and Concrete Research, 41(12), 1289-1309. 2011.

[2] MA, S., LI, W., ZHANG, S., GE, D., YU, J., \& SHEN, X. Influence of sodium gluconate on the performance and hydration of Portland cement. Construction and Building Materials, 91, 138144. 2015.

[3] ATAIE, F. F., JUENGER, M. C., TAYLOR-LANGE, S. C., \& RIDING, K. A. Comparison of the retarding mechanisms of zinc oxide and sucrose on cement hydration and interactions with supplementary cementitious materials. Cement and Concrete Research, 72, 128-136. 2015.

[4] CEPURITIS, R., JACOBSEN, S., SMEPLASS, S., MØRTSELL, E., WIGUM, B. J., \& NG, S. Influence of crushed aggregate fines with micro-proportioned particle size distributions on rheology of cement paste. Cement and Concrete Composites. 2017.

[5] RICKERT, J. Influence of Retarders on the Hydration of Clinker and Cement. Concrete Technology Reports, 2001.

[6] BESSAIES-BEY, H., BAUMANN, R., SCHMITZ, M., RADLER, M., \& ROUSSEL, N. Organic admixtures and cement particles: Competitive adsorption and its macroscopic rheological consequences. Cement and Concrete Research, 80, 1-9. 2016.

[7] TALERO. R, PEDRAJAS. C, GONZÁlEZ. M, ARAMBURO. C, BLÁZQUEZ. A, RAHHAL.V. Role of the filler on Portland cement hydration at very early ages: Rheological behaviour of their fresh cement pastes. Construction and Building Materials, 151, 939-949, 2017. 